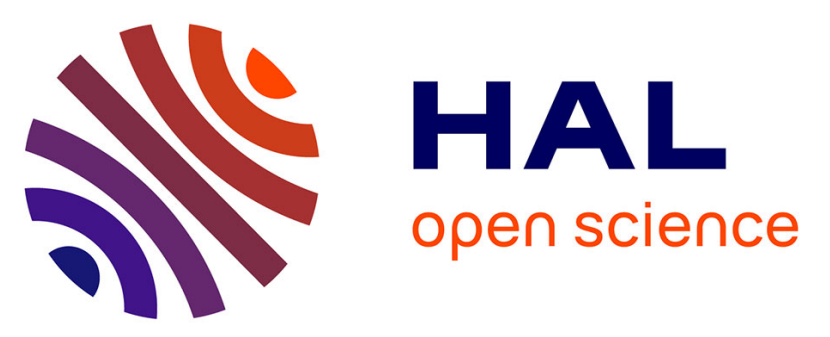

\title{
Germline mutations of the CBL gene define a new genetic syndrome with predisposition to juvenile myelomonocytic leukemia (JMML)
}

Benoite Pérez, Françoise Mechinaud, Claire Galambrun, Neila Benromdhan, Bertrand Isidor, Nicole Philip, Justine Derain-Court, Bruno Cassinat, Julie Lachenaud, Sophie Kaltenbach, et al.

\section{To cite this version:}

Benoite Pérez, Françoise Mechinaud, Claire Galambrun, Neila Benromdhan, Bertrand Isidor, et al. Germline mutations of the CBL gene define a new genetic syndrome with predisposition to juvenile myelomonocytic leukemia (JMML). Journal of Medical Genetics, 2010, 47 (10), pp.686. 10.1136/jmg.2010.076836 . hal-00557393

\section{HAL Id: hal-00557393 \\ https://hal.science/hal-00557393}

Submitted on 19 Jan 2011

HAL is a multi-disciplinary open access archive for the deposit and dissemination of scientific research documents, whether they are published or not. The documents may come from teaching and research institutions in France or abroad, or from public or private research centers.
L'archive ouverte pluridisciplinaire $\mathbf{H A L}$, est destinée au dépôt et à la diffusion de documents scientifiques de niveau recherche, publiés ou non, émanant des établissements d'enseignement et de recherche français ou étrangers, des laboratoires publics ou privés. 


\section{GermLine mutations of the CBL Gene define a NEW GenetiC SYNDROME WITH PREDISPOSION TO JUVENILE MYELOMONOCYTIC LEUKEMIA (JMML)}

B Pérez ${ }^{1,2}, \mathrm{~F} \mathrm{Mechinaud}^{3}$, C Galambrun ${ }^{4}$, N Ben Romdhane ${ }^{5}$, B Isidor ${ }^{6}$, N Philip ${ }^{7}$, J Derain-Court ${ }^{7}$, B Cassinat ${ }^{2}$, J Lachenaud ${ }^{1,2}, \mathrm{~S}$ Kaltenbach ${ }^{1}$, A Salmon ${ }^{8}$, C Désirée ${ }^{1}, \mathrm{~S}$ Pereira ${ }^{1}, \mathrm{ML}$ Menot ${ }^{2}, \mathrm{~N}$ Royer ${ }^{9}$, O Fenneteau ${ }^{10}, \mathrm{~A}$ Baruchel ${ }^{11}, \mathrm{C}$ Chomienne $^{2}$, A Verloes ${ }^{1,12}$ and $\mathrm{H}$ Cavé ${ }^{1,2}$

Corresponding author: Hélène Cavé, Laboratoire de Biochimie Génétique, Hôpital Robert Debré, 48, Boulevard Sérurier, 75019 Paris, France.

Tel: 33-(0)1 40035711

Fax: 33-(0)1 40032277

E-mail: helene.cave@rdb.aphp.fr

Word count:

- abstract: 216

- main text: 3202

Figures: 3

References: 27 


\section{ABSTRACT}

\section{Background:}

CBL missense mutations have recently been associated with juvenile myelomonocytic leukemia (JMML), an aggressive myeloproliferative and myelodysplatic neoplasm of early childhood characterized by excessive macrophage/monocyte proliferation. CBL, an E3 ubiquitin ligase and a multi adaptor protein, controls proliferative signaling networks by downregulating the growth factor receptor signaling cascades in various cell types.

\section{Methods and results:}

$C B L$ mutations were screened in 65 patients with JMML. A homozygous mutation of $C B L$ was found in leukemic cells of $4 / 65(6 \%)$ patients. In all cases, copy neutral loss of heterozygosity of the 11q23-qter chromosomal region, encompassing the CBL locus, was demonstrated. Three of these 4 patients displayed additional features suggestive of an underlying developmental condition. A heterozygous germline $C B L$ p.Y371 $\mathrm{H}$ substitution was found in each of them and was inherited from the father in one patient. The germline mutation represents the first hit, with somatic loss of heterozygosity being the second hit positively selected in JMML cells. The 3 patients display a variable combination of dysmorphic features, hyperpigmented skin lesions and microcephaly that allow us to tentatively delineate a "CBL syndrome". Learning difficulties and postnatal growth retardation may be part of the phenotype.

\section{Conclusion:}

We report germline mutations of $\mathrm{CBL}$ in 3 patients with $\mathrm{JMML}$, confirming the existence of an unreported inheritable condition associated with a predisposition to JMML.

Key words: JMML, CBL, microcephaly, cancer predisposition 


\section{INTRODUCTION}

The Casitas B-cell lymphoma ( $\mathrm{CBL}, \mathrm{c}-\mathrm{CBL}$ ) protein is a member of the $\mathrm{CBL}$ family of E3 ubiquitin ligases. $C B L$ controls proliferative signaling networks by downregulating the growth factor receptor signaling cascades. ${ }^{1,2} \mathrm{CBL}$ contains a tyrosine kinase binding (TKB) domain and a Zinc-binding RING finger domain that mediates the E3 ubiquitin ligase activity. These two highly conserved domains are separated by a short linker sequence crucial for ubiquitin ligase activity of CBL. ${ }^{1}$ The E3 ligase activity directs the mono-ubiquitination of activated receptors at multiple sites, which promotes endocytosis and lysosomal degradation of the receptors. ${ }^{2} \mathrm{CBL}$ is also involved in many signaling events through its function as a multiadaptor protein.

CBL missense mutations have recently been associated with acute myeloid leukemia $^{3,4}$ various myeloproliferative neoplasms ${ }^{5,6}$ and juvenile myelomonocytic leukemia $(\mathrm{JMML}){ }^{7} \mathrm{JMML}$ is an aggressive myeloproliferative and myelodysplatic neoplasm of early childhood characterized by excessive macrophage/monocyte proliferation that infiltrates hematopoietic and non hematopoietic tissues. ${ }^{8}$ The natural course of JMML is rapidly fatal. Progression to acute leukemia is infrequent, but most children die from progressive respiratory and multivisceral failure. Allogenic bone marrow transplantation is the only curative therapy, achieving long term survival in about half of the patients. Cells from affected patients are abnormally sensitive to granulocyte-macrophage colony stimulating factor (GM-CSF). This hypersensitivity is the result of the pathological activation of the RAS signaling pathway by mutations of NRAS, KRAS, NF1, PTPN11 or CBL. ${ }^{7,8}$ In JMML, CBL mutations were found to target preferentially amino-acid $\mathrm{Y} 371$ in the linker region, whereas mutations affecting this amino-acid are rare in other myeloid neoplasms. As in other myeloid malignancies, $C B L$ mutations found in JMML are associated with loss of the non mutated $C B L$ allele by acquired uniparental disomy of the 11q23 chromosomal region. $^{5,9}$

JMML has been observed in association with congenital malformations, including neurofibromatosis type 1 (NF1) (OMIM 162200) and Noonan syndrome (NS) (OMIM 163950), two conditions associated with RAS pathway deregulation. ${ }^{8}$ Patients with NF1 display loss of the normal NF1 allele in cancer cells. ${ }^{10}$ Patient with NS and 
JMML usually harbor activating heterozygous germline mutations in PTPN $11^{11}$ and more rarely, in $K R A S^{12}$, or $N R A S^{13}$.

Germline CBL mutation was suspected in one patient by Loh et al. ${ }^{7}$ who detected a heterozygous p.Y371H CBL mutation in cord blood and a homozygous p.Y371H mutation in JMML cells. We confirm here that some patients with JMML can harbor germline mutations of $\mathrm{CBL}$ by reporting 3 further patients among a cohort of 65 JMML patients. Our observations suggest that constitutional $C B L$ mutations lead to a constellation of mild, variable developmental defects and predisposition to JMML, which could be tentatively described as a "CBL syndrome".

\section{PATIENTS / METHODS}

\section{Patient 1}

\section{General history}

Patient 1 was born at 38 weeks of gestation (WG). Her mother had gestational diabetes. Birth weight (BW) was $3020 \mathrm{~g}$ (-0.6 SD), birth length (BL) $45 \mathrm{~cm}(-2.4 \mathrm{SD})$, occipito-frontal head circumference (OFC) $32 \mathrm{~cm}(-2.2 \mathrm{SD})$. She had failure to thrive, with poor sucking and postnatal growth retardation. She walked at the age of 24 months (mo). She uttered her first words at 23 mo. Subsequent development of speech was severely delayed. She had normal hearing and normal ophthalmologic examination. She developed a JMML at age $26 \mathrm{mo}$. At first evaluation, in the genetic department of Nantes, at age $30 \mathrm{mo}$, she was $78 \mathrm{~cm}$ tall (-3 SD), had a weight of 9.6 $\mathrm{kg}(-2.1 \mathrm{SD})$ an OFC of $44.5 \mathrm{~cm}(-2.7 \mathrm{SD})$. She was felt to be mildly dysmorphic, disclosing broad forehead, hypertelorism, epicanthic folds, deeply grooved philtrum, thick lips, mild retrognathism, thick, posteriorly rotated but normally set ears with overfolded helices, short neck, thin hair and low posterior hairline (Figure 1 A-B). She had a single café-au-lait spot on the abdomen. She had no thoracic or spinal deformities. The cardiac ultrasound scan was normal. The cerebral MRI was normal. She was hyperactive, with short attention span and poor verbal skills. At that time, a diagnosis of mild Noonan syndrome was tentatively suggested. At last evaluation, 
aged four years (y) six mo, her height was $96 \mathrm{~cm}$ (-1.7 SD), her weight was $13.7 \mathrm{~kg}$ (1.3 SD) and her OFC is $47 \mathrm{~cm}(-2.2 \mathrm{SD})$.

\section{Family history}

This girl was the second child of healthy non consanguineous parents aged 27y and $22 y$ at time of her birth. The father was $180 \mathrm{~cm}$ tall (+ $0.8 \mathrm{SD}$ ). He has no personal or familial history of hematologic malignancies. He had a vocational training qualification. The mother was $155 \mathrm{~cm}$ (- $1.5 \mathrm{SD})$. Several relatives of the mother had adult-onset cancers of various types.

\section{Hematological history}

At age 26 mo, she was hospitalized for massive hepatosplenomegaly, retroperitoneal and mesenteric lymphadenopathies, hyperleucocytosis $\left(46 \times 10^{9} / \mathrm{L}\right)$, thrombocytopenia $\left(46 \times 10^{9} / \mathrm{L}\right)$ and anemia $(8.4 \mathrm{~g} / \mathrm{dl})$. The peripheral differential blood count showed: $17 \%$ monocytes $\left(7.6 \times 10^{9} / \mathrm{L}\right), 18 \%$ immature granulocytes and $3 \%$ blasts. The bone marrow aspirate was hypercellular with granulocytic proliferation but without excess of blasts. These features were consistent with a diagnosis of JMML. She received cord blood, then relapsed and benefited from a second cord blood allograft. She is alive, 16 months after the second allograft and displays complete donor chimerism.

\section{Patient 2}

\section{General history}

Patient 2 was born in Tunisia at 41 WG by caesarean section for dystocia. Birth Weight: $3100 \mathrm{~g}$ (-0.4 SD), birth length $50 \mathrm{~cm}$ (-0.9 SD), OFC $34 \mathrm{~cm} \mathrm{(-1} \mathrm{SD).} \mathrm{The}$ pregnancy was uneventful. She had postnatal failure to thrive. At age 1 year, her height was $71 \mathrm{~cm}$ (-0.6 SD), her weight was $8 \mathrm{~kg}(-1.2 \mathrm{SD})$ and her OFC is $44 \mathrm{~cm}$ (1.1 SD). At last evaluation, at age 24 mo she weighted $8 \mathrm{~kg}$ (-3 SD), her height was $77 \mathrm{~cm}$ (-2.4 SD) and her OFC was $44.5 \mathrm{~cm}$ (-2.4 SD). She had microcephaly, triangular facies, high cranial vault, bilateral epicanthic folds, thick lips, prominent philtrum, posteriorly rotated helices and somewhat sparse hair (Figure 1 C-D). The cardiac echocardiogram was normal. She has no skin anomalies. T2-weighted Flair MRI showed non-specific hyperintense signals in the periventricular white matter. Neurological examination was normal. Psychomotor development was appropriate 
for age (walked at 18 months, first words at 12 months). Bone age was mildly delayed (18 mo at age $22 \mathrm{mo}$ ). IGF1 was $12 \mathrm{nmol} / \mathrm{l}$ (normal 4 to $22 \mathrm{nmol} / \mathrm{l}$ ) and IGFBP-3 $1100 \mathrm{ng} / \mathrm{ml}$ (normal 1090 to $2490 \mathrm{ng} / \mathrm{ml}$ ).

\section{Family history}

She was the only child from healthy first cousins parents. The mother was $26 y$ old and the father $39 \mathrm{y}$ old at birth. The father was $168 \mathrm{~cm}$ tall $(-0.6 \mathrm{SD})$ and the mother $160 \mathrm{~cm}(-1.2 \mathrm{SD})$. The family history was not contributory.

\section{Hematological history}

A diagnosis of JMML was made at 13 months of age because of persistent hyperleucocytosis $\left(50 \times 10^{9} / \mathrm{L}\right)$, thrombocytopenia $\left(35.10^{9} / \mathrm{L}\right)$ and hepatosplenomegaly. The peripheral differential blood count showed: $19 \%$ monocytes $\left(9.5 \times 10^{9} / \mathrm{L}\right), 9 \%$ immature granulocytes and $0.5 \%$ blasts. The bone marrow was hypercellular with granulocytic proliferation and no excess of blasts. At age 24 months, she received a cord blood allograft. She remains alive at age 25 months. A mixed chimerism (50\% donor) was found 30 days after the allograft.

\section{Patient 3}

\section{General history}

Patient 3 was born at 39 WG. Her mother had gestational diabetes. BW: $3240 \mathrm{~g}(-0.1$ $\mathrm{SD}), \mathrm{BL} 50 \mathrm{~cm}$ (+ $0.3 \mathrm{SD})$, OFC $35 \mathrm{~cm}(+0.55 \mathrm{SD})$. At age $12 \mathrm{mo}$, she was $70.5 \mathrm{~cm}$ tall (-0.8 SD), and weighted $8.8 \mathrm{~kg}(-0.4 \mathrm{SD})$ and her OFC was $45 \mathrm{~cm}(-0.25 \mathrm{SD})$. She had a broad forehead, arched eyebrows, hypertelorism, palpebral ptosis, short, upturned nose, flat malar areas, deeply grooved philtrum, posteriorly rotated but normally set ears with thick helices and large lobules (Figure $1 \mathrm{E}-\mathrm{F}$ ). Pectus excavatum and hypermobile finger joints were present. Her skin was hyperelastic and she presented redundant skinfolds on hands and feet. Three café-au-lait spots (smaller than $2 \mathrm{~cm}$ ) were present on the back and two on the anterior part of the thighs. The cardiac ultrasound and cerebral MRI were normal. Neurological, ophthalmologic examinations and hearing test were normal. She walked unsupported at age $14 \mathrm{mo}$ and uttered her first words at $18 \mathrm{mo}$. She displayed a postnatal decline of her OFC (at age 2 years her OFC was $46 \mathrm{~cm}(-1.2 \mathrm{SD}$ ) and at age 3 years $47.5 \mathrm{~cm}$ 
(-1.1 SD)). At last evaluation, aged six years, her height was $107 \mathrm{~cm}(-1.4 \mathrm{SD})$ and her weight was $15 \mathrm{~kg}$ (-1.9 SD). She had normal schooling (first grade) and no learning disabilities.

\section{Family history}

This girl was the only child of healthy non consanguineous parents aged 27y and 23y at the time of her birth. The father was $193 \mathrm{~cm}$ tall $(+3.0 \mathrm{SD})$ and the mother $153 \mathrm{~cm}$ $(-1.8 \mathrm{SD})$. The family history was not contributory.

\section{Hematological history}

At age $12 \mathrm{mo}$, she was hospitalized for massive splenomegaly, hyperleucocytosis $\left(30 \times 10^{9} / \mathrm{L}\right)$, mild thrombocytopenia $\left(136 \times 10^{9} / \mathrm{L}\right)$ and anemia $(9.4 \mathrm{~g} / \mathrm{d})$ ). The peripheral differential blood count showed: $22 \%$ monocytes $(6.6 \times 10 \% / L), 5 \%$ immature granulocytes and $1 \%$ blast. The bone marrow aspirate was hypercellular with granulocytic proliferation but without excess of blasts. She had a cord blood allograft. She had no relapse 4 years and 9 months after the allograft. She has complete donor chimerism.

\section{Genetic analysis}

Parents gave written consent for genetic analysis and clinical photographs.

\section{Karyotyping}

Conventional cytogenetic analysis was performed on peripheral blood and bone marrow using standard procedures.

\section{Mutation screening}

Bone marrow aspirates and peripheral blood were collected on EDTA at diagnosis. Genomic DNA was extracted from mononucleated hematopoietic cells, fibroblasts or buccal swabs using Qiagen Mini or Midi Kit (Qiagen Ltd). Mutation screening was performed by bi-directional sequencing of exons and their flanking intron-exon boundaries as described previously. ${ }^{14}$ The entire coding region of KRAS and NRAS was screened. PTPN11 screening was restricted to exons 2, 3, 4, 7, 8, 12, 13, 14 and $C B L$ screening to exons 7, 8 and 9. GenBank accession number for $C B L$ 
genomic and mRNA reference sequences are NM_005188 and NC_000011 respectively.

\section{Microsatellite analysis}

Loss of heterozygosity ( $\mathrm{LOH}$ ) at $\mathrm{CBL}$ locus was assessed by PCR amplification of 9 microsatellite markers covering the 11q arm: D11S1294 (11q22.3), D11S4206 (11q22.3), D11S4129 (11q22.3), D11S924 (11q22.3), D11S4171 (11q22.3), D11S1774 (11q22.3), D11S925 (11q23), D11S934 (11q23-24), D11S968 (11q25).

$\mathrm{LOH}$ at NF1 locus was assessed by PCR amplification of 8 microsatellite markers covering the $17 q$ arm located within or close to the $N F 1$ gene respectively. ${ }^{15}$

Family links were checked by testing a panel of 16 microsatellite using the powerplex ${ }^{\circledR}$ kit (Promega).

\section{SNP array analysis}

Tumor (bone marrow cells) and fibroblasts DNA were hybridized to Affymetrix Genome-Wide Human SNP 6.0 Arrays. CEL files were created using the Affymetrix GeneChip Command Console operating software and Genotyping Console 2.1, according to the manufacturer's protocols (Affymetrix). The Partek Genomics Suite was used for both copy number alteration (CNA) and LOH analysis. Regions of CNA were detected using a Hidden Markov Model algorithm in the standard Partek workflow for paired samples. LOH used genotyping results from paired germinal and tumor samples and Partek LOH workflow.

\section{Myeloid progenitor cell growth}

In vitro growth of myeloid progenitors was performed by plating bone marrow and peripheral blood mononucleated cells in semi-solid methylcellulose with and without leukocyte conditioned medium (cytokines medium, LCM, StemCell Technologies Inc, Vancouver, Canada) as described previously. ${ }^{16}$ Colonies (aggregates containing $>50$ cells) were scored at day 11 and 14. "Endogenous growth" corresponded to the presence of CFU (CFU-GM>10 colonies or CFU-M>5 colonies) in absence of growth factors. 


\section{RESULTS}

$C B L$ mutations were screened in a cohort of 65 unselected patients with JMML. A homozygous mutation of $C B L$ was found in leukemia cells of 4/65 (6\%) patients. In all patients, copy neutral loss of heterozygosity of the 11q23-qter chromosomal region, encompassing the CBL locus, was demonstrated by SNP array (Figure 2) and microsatellite analysis. No RAS activating mutation in NRAS, KRAS, or PTPN11 gene (classically associated with JMML) was detected. None of the patients had phenotypic feature evocative of NF1, except for some café-au-lait spots in patients 1 and 3. Mitotic recombination leading to loss of heterozygosity and subsequent inactivation of both NF1 alleles is virtually constant in JMML of patients with neurofibromatosis. ${ }^{10}$ No loss of heterozygosity at the NF1 locus was present in the leukemia cells of our 3 patients, making unlikely the presence of a NF1 in these children.

One JMML patient had a c. $1254 C>G$ homozygous transversion in exon 9 of $C B L$, resulting in the p.F418L missense amino acid substitution. The three others had a c.1111T >C homozygous transition (in exon 8), resulting in the p.Y371H missense amino acid substitution (Figure 3.1). These patients displayed additional features suggestive of an underlying developmental condition. All three had normal blood and bone marrow karyotype. A heterozygous germline p.Y371 H substitution was found in fibroblasts in each of them (Figure 3.2). DNA of jugal mucosa (obtained from buccal swabs) was tested in patients 2 and 3 and also showed the presence of the germline p.Y371H substitution. In patient 1 , despite a family history of cancer in maternal lineage, the mutation was inherited from the father (Figure 3.4). Mutation occurred de novo in the 2 other patients (Figure 3.4).

These three patients fulfilled all the JMML diagnosis criteria reported at the last JMML international symposium ${ }^{17}$ and their presentation did not significantly differ from that observed in the other patients (age at diagnosis, WBC count...). Myeloid progenitors from blood and bone marrow showed an endogenous growth pattern in the absence of growth factors, as classically observed in JMML (data not shown).

The three children present slightly dysmorphic traits. Two patients have multiple caféau-lait spots. Two have microcephaly below -2 SD. Patient 1 had short birth length, and secondary catch up ending in low normal stature at age 4.5 years. Patient 2 had 
true growth decline during her second year of life, ending with true postnatal growth retardation. No growth retardation was noted in patient 3 and in the father of patient 1.

\section{DISCUSSION}

We identified constitutional heterozygous missense mutations of $C B L$ in three unrelated patients with $\mathrm{JMML}$, confirming the existence of a currently unrecognized dominantly inherited condition with propensity to develop myeloproliferative neoplasm (JMML) in early infancy. Our patients carried the recurrent p.Y371H substitution, inherited from the father in one instance. The process of tumorigenesis observed in our patients is in line with the classical Knudson hypothesis for tumor suppressor genes: the first hit is germline while the second hit occurs somatically and is selected for in JMML cells. Phosphorylation of Y371 is essential for the E3 activity of CBL and for its interaction with a number of signaling proteins. Phospho-Tyr-371 appears to play a role in the interactions of $\mathrm{c}-\mathrm{Cb}$ with $\mathrm{PI} 3$ kinase (PI3K). ${ }^{2}$ Substitution of $\mathrm{Y} 371$ can have different consequences: mutants of $\mathrm{CBL}$ lacking $\mathrm{Y} 371$ are oncogenic, ${ }^{18}$ Y371F mutants are inactive in auto-ubiquitylation assays in vitro, while Y371E mutants apparently mimic phosphorylated tyrosines and are constitutively active. ${ }^{2}$

Although our series is small, we found subtle developmental anomalies in all patients. Mild hypertelorism, short upturned nose, deeply grooved philtrum and thick lips, reminiscent of the facial Gestalt of Noonan syndrome, are observed in the 3 patients. Two patients have café-au-lait spots. Patient 1 had short stature at birth and low normal height at last evaluation, whereas patient 2 showed progressive growth retardation. These two children have mild microcephaly, present at birth in one of them. In patient 1, developmental milestones are delayed. For patient 2, there is no major developmental anomaly, but her young age precludes any firm conclusion. Patient 3 had a normal head circumference at birth and presented a postnatal decline of her OFC. She had a normal development, as did patient 1's father. Although these anomalies could have occurred by chance, presence of some dysmorphic signs in each patient lead us to raise the hypothesis that $C B L$ haploinsufficiency may interfere 
with normal somatic and cerebral development. Unfortunately, no phenotypic data are available for the only other patient with constitutional $C B L$ mutation reported by Loh et al. ${ }^{7}$ At this point, these somewhat conflicting observations do not allow us to make a firm conclusion, considering the possible confounding effects of JMML development itself, and of therapeutic and nutritional interventions. The dysmorphic traits are subtle, and need to be confirmed by independent reports and long term follow-up, but the fact that Noonan syndrome was discussed in case 1 prior to the discovery of the CBL anomaly has to be underlined. Time will tell if our seminal observations represent the first step in the delineation of a " $\mathrm{CBL}$ syndrome".

RAS activation is known to play a central role in sporadic and syndromic JMML. CBL germline mutations are associated with a propensity to develop JMML suggesting that they induce RAS pathway activation. However, they are associated with a phenotype that is distinct from Noonan syndrome, neurofibromatosis, or any other disorder belonging to the spectrum of RAS/MAPK activation syndrome. Significantly, congenital heart defect were not observed in our patients.

Abnormalities in the ubiquitylation system have been implicated in the pathogenesis of various human disease including malignant transformation and several genetic diseases. ${ }^{19}$ Knock-out of either the $\mathrm{Cbl}$ or Cbl-b genes in mice are mainly characterized by a phenotype in the lymphocyte compartment. ${ }^{20,21}$ However, $\mathrm{Cbl}^{-/-}$ mice also display a relatively mild phenotype in other cell types. In addition, recent data suggest that mutations do not lead to the simple knock-out of Cbl function but render it a proto-oncogene. ${ }^{22}$ Mutant $\mathrm{CBL}$ inhibits ubiquitination of growth factor receptors even in the presence of a normal copy of the CBL gene, leading to enhanced proliferative response to growth factors. ${ }^{6,22}$ Altogether, these observations are consistent with a phenotypic expression of $\mathrm{CBL}$ heterozygous mutation.

The importance of $\mathrm{Cbl}$ in hematopoiesis has been demonstrated in knock-out mice that show hyper-responsiveness to hematopoietic growth factors, expansion of the progenitor and stem cell pool, and mild myeloproliferative features. ${ }^{22}$ The observation of a propensity to develop JMML in children with $\mathrm{CBL}$ germline mutations as well as the close association of $\mathrm{CBL}$ mutations with other monocyte expansion, such as that seen in CMML or in $A M L$ with monocytoid features suggest a primary role for $\mathrm{CBL}$ mutations in the pathogenesis of these disease. The reason for the specific impact of $\mathrm{CBL}$ on the monocytic lineage and the role of RAS in this process has to be clarified. 
Intriguingly, Chiusaroli et al. reported that growth is transiently delayed in $\mathrm{Cbl}^{-1-}$ mice. ${ }^{23}$ This could be explained by a delayed replacement of cartilage by bone as a consequence of a decreased motility of osteoclasts. $\mathrm{CBL}$ inactivation may also interfere with growth hormone $(\mathrm{GH})$ signalling. ${ }^{24}$

How can we understand the presence of microcephaly in 2/3 patients? Dysregulation of neuroepithelial progenitors proliferation and survival is suspected to be a major cause of primary microcephaly. ${ }^{25}$ Loss of CBL function, by contributing to the activation of the JNK pathway, may sensitize healthy neuronal cells to death. ${ }^{26}$ It has been recently shown that deficiency of the small GTPase Rac-1 in mouse forebrain causes microcephaly by increasing apoptosis and defective differentiation. ${ }^{27}$ Thus, decreased activation of RAC-1 by CBL may also play a role by inducing a pro-death signaling cascade. ${ }^{2}$

In conclusion, presence of germline alteration of $\mathrm{CBL}$ yields a relatively mild phenotype in childhood, possibly because of partial redundancy of CBL and CBL-b functions. However, it raises several concerns for the follow-up of those patients. Inappropriate activation of mammalian protein tyrosine kinases (PTK) can lead to various forms of human cancers. Could CBL mutation predispose to other malignancies, or to secondary solid tumors in JMML survivors? Which prevention strategy should be proposed?

\section{Acknowledgements:}

We thank the families for active participation in the study and for providing us with written consent for publication of their clinical and molecular data.

We thank B Leheup for his advice in patient 3 and RA Padua for reviewing the manuscript.

SNP-array analyses have been performed in the "Plateforme de Génomique du GHU Nord" (J Soulier, S Quentin, P Luizzi).

This work was supported in part by a grant from Enfant \& Santé and the Société Française de lutte contre les Cancers et les leucémies de l'Enfant et l'adolescent (SFCE). 


\section{Affiliations:}

B Pérez ${ }^{1,2}, \mathrm{~F}_{\text {Mechinaud }}{ }^{3}, \mathrm{C}$ Galambrun ${ }^{4}, \mathrm{~N}$ Ben Romdhane ${ }^{5}$, B Isidor ${ }^{6}$, N Philip ${ }^{7}$, $\mathrm{J}_{\text {Derain-Court }}{ }^{7}$, B Cassinat ${ }^{2}$, J Lachenaud ${ }^{1,2}$, S Kaltenbach ${ }^{1}$, A Salmon ${ }^{8}$, C Désirée ${ }^{1}$, S Pereira ${ }^{1}$, ML Menot ${ }^{2}$, N Royer ${ }^{9}$, O Fenneteau ${ }^{10}$, A Baruchel ${ }^{11}, \mathrm{C}$ Chomienne $^{2}$, A Verloes ${ }^{1,12}$ and H Cavé ${ }^{1,2}$

1. APHP, Hôpital Robert Debré, Département de Génétique; Université Paris 7-Denis Diderot, Paris, France

2. INSERM U940, Institut Universitaire d'Hématologie (IUH), Hôpital Saint Louis, Paris, France

3. Service d'Oncologie Hématologie Pédiatrique, CHRU, Nantes, France

4. Service d'Hématologie Pédiatrique, Hôpital de la Timone, Marseille, France

5. Service d'Hématologie, Hopital La Rabta, Tunis

6. Service de Génétique, CHRU, Nantes, France

7. Service de Génétique, Hôpital de la Timone, Marseille, France

8. Service d'Onco-Hématologie Pédiatrique, CHRU, Nancy, France

9. APHP, Hôpital Robert Debré, Service de Biochimie-Hormonologie, Paris, France

10. APHP, Hôpital Robert Debré, Service d'Hématologie Biologique, Paris, France

11. APHP, Hôpital Robert Debré, Service d'Hématologie Pédiatrique ; Université Paris 7-Denis Diderot, Paris, France

12. INSERM U676, Hôpital Robert Debré, Paris, France

Corresponding author: Hélène Cavé, Laboratoire de Biochimie Génétique, Hôpital Robert Debré, 48, Boulevard Sérurier, 75019 Paris, France.

Tel: 33-(0)14003 5711

Fax: 33-(0)1 40032277

E-mail: helene.cave@rdb.aphp.fr

Competing interests: none declared

Patient consent: obtained 


\section{REFERENCES}

1 Schmidt $\mathrm{MH}$, Dikic I. The Cbl interactome and its functions. Nat Rev Mol Cell Biol 2005;6(12):907-18.

2 Swaminathan G, Tsygankov AY. The Cbl family proteins: ring leaders in regulation of cell signaling. J Cell Physiol 2006;209(1):21-43.

3 Caligiuri MA, Briesewitz R, Yu J, et al. Novel c-CBL and CBL-b ubiquitin ligase mutations in human acute myeloid leukemia. Blood 2007;110(3):1022-4.

4 Sargin B, Choudhary C, Crosetto N, et al. Flt3-dependent transformation by inactivating c-Cbl mutations in AML. Blood 2007;110(3):1004-12.

5 Dunbar AJ, Gondek LP, O'Keefe CL, et al. 250K single nucleotide polymorphism array karyotyping identifies acquired uniparental disomy and homozygous mutations, including novel missense substitutions of c-Cbl, in myeloid malignancies. Cancer Res 2008;68(24):10349-57.

6 Grand $\mathrm{FH}$, Hidalgo-Curtis $\mathrm{CE}$, Ernst $\mathrm{T}$, et al. Frequent $\mathrm{CBL}$ mutations associated with 11q acquired uniparental disomy in myeloproliferative neoplasms. Blood 2009;113(24):6182-92.

7 Loh ML, Sakai DS, Flotho C, et al. Mutations in CBL occur frequently in juvenile myelomonocytic leukemia. Blood 2009;114(9):1859-63.

8 Flotho C, Kratz CP, Niemeyer CM. How a rare pediatric neoplasia can give important insights into biological concepts: a perspective on juvenile myelomonocytic leukemia. Haematologica 2007;92(11):1441-6.

9 Fitzgibbon J, Smith LL, Raghavan M, et al. Association between acquired uniparental disomy and homozygous gene mutation in acute myeloid leukemias. Cancer Res 2005;65(20):9152-4.

10 Shannon KM, O'Connell P, Martin GA, et al. Loss of the normal NF1 allele from the bone marrow of children with type 1 neurofibromatosis and malignant myeloid disorders. N Engl J Med 1994;330(9):597-601.

11 Tartaglia M, Niemeyer CM, Fragale A, et al. Somatic mutations in PTPN11 in juvenile myelomonocytic leukemia, myelodysplastic syndromes and acute myeloid leukemia. Nat Genet 2003;34(2):148-50.

12 Schubbert S, Zenker M, Rowe SL, et al. Germline KRAS mutations cause Noonan syndrome. Nat Genet 2006;38(3):331-6.

13 De Filippi $\mathrm{P}$, Zecca M, Lisini D, et al. Germ-line mutation of the NRAS gene may be responsible for the development of juvenile myelomonocytic leukaemia. Br J Haematol 2009;147(5):706-9.

14 Keren B, Hadchouel A, Saba S, et al. PTPN11 mutations in patients with LEOPARD syndrome: a French multicentric experience. $J$ Med Genet 2004;41(11):e117.

15 Kluwe L, Siebert R, Gesk S, et al. Screening 500 unselected neurofibromatosis 1 patients for deletions of the NF1 gene. Hum Mutat 2004;23(2):111-6.

16 Cambier $\mathrm{N}$, Menot $\mathrm{ML}$, Schlageter $\mathrm{MH}$, et al. All trans retinoic acid abrogates spontaneous monocytic growth in juvenile chronic myelomonocytic leukaemia. Hematol J 2001;2(2):97-102. 
17 Chan RJ, Cooper T, Kratz CP, et al. Juvenile myelomonocytic leukemia: a report from the 2nd International JMML Symposium. Leuk Res 2009;33(3):355-62.

18 Kassenbrock CK, Anderson SM. Regulation of ubiquitin protein ligase activity in $\mathrm{c}-\mathrm{Cbl}$ by phosphorylation-induced conformational change and constitutive activation by tyrosine to glutamate point mutations. I Biol Chem 2004;279(27):28017-27.

19 Schwartz AL, Ciechanover A. Targeting proteins for destruction by the ubiquitin system: implications for human pathobiology. Annu Rev Pharmacol Toxicol 2009;49:73-96.

20 Murphy MA, Schnall RG, Venter DJ, et al. Tissue hyperplasia and enhanced T-cell signalling via ZAP-70 in c-Cbl-deficient mice. Mol Cell Biol 1998;18(8):4872-82.

21 Chiang YJ, Kole HK, Brown K, et al. Cbl-b regulates the CD28 dependence of T-cell activation. Nature 2000;403(6766):216-20.

22 Sanada M, Suzuki T, Shih LY, et al. Gain-of-function of mutated C-CBL tumour suppressor in myeloid neoplasms. Nature 2009;460(7257):904-8.

23 Chiusaroli R, Sanjay A, Henriksen K, et al. Deletion of the gene encoding c$\mathrm{Cbl}$ alters the ability of osteoclasts to migrate, delaying resorption and ossification of cartilage during the development of long bones. Dev Biol 2003;261(2):537-47.

24 Goh EL, Zhu T, Leong WY, et al. c-Cbl is a negative regulator of GHstimulated STAT5-mediated transcription. Endocrinology 2002;143(9):3590603.

25 Rakic P. A small step for the cell, a giant leap for mankind: a hypothesis of neocortical expansion during evolution. Trends Neurosci 1995;18(9):383-8.

26 Sproul AA, Xu Z, Wilhelm M, et al. Cbl negatively regulates JNK activation and cell death. Cell Res 2009;19(8):950-61.

27 Chen L, Melendez J, Campbell K, et al. Rac1 deficiency in the forebrain results in neural progenitor reduction and microcephaly. Dev Biol 2009;325(1):162-70. 
"The Corresponding Author has the right to grant on behalf of all authors and does grant on behalf of all authors, an exclusive licence (or non exclusive for government employees) on a worldwide basis to the BMJ Publishing Group Ltd to permit this article (if accepted) to be published in JMG and any other BMJPGL products and sublicences such use and exploit all subsidiary rights, as set out in our licence (http://group.bmj.com/products/journals/instructions-for-authors/licence-forms)." 


\section{FIGURE LEGENDS}

Figure 1: Photographs of the three patients.

A, C, E: frontal facial view of patient 1 (at 4 years 6 months of age), of patient 2 (at 24 months of age), of patient 3 (at 6 years of age).

B, D, F: lateral facial view of patient 1 (at 30 months of age), of patient 2 (at 24 months of age), of patient 3 (at 6 years of age).

Figure 2: Single nucleotide polymorphism array profile of chromosome 11 (Affymetrix SNP6.0 technology and Partek image) showing the copy-neutral LOH of tumor versus germinal DNA for patient 1. The red line represents average copy number signal intensity of SNPs on the array chip. In this instance, there are no CN variations and the red line does not deviate from normal diploid $\mathrm{CN}$. The graph above chromosome ideogram represents the allele specific copy number and indicates copy-neutral LOH. White box represent UPD region.

Figure 3: Germline $C B L$ mutations. Sequence electrophoregrams documenting the c. $1111 \mathrm{~T}>\mathrm{C}$ mutation found in exon 8 of $C B L$ gene for these three patients:

3.1, DNA at time of the leukemia diagnosis; 3.2, DNA from cultured fibroblasts; 3.3 , maternal DNA; 3.4, paternal DNA. Asterisks $\left(^{*}\right)$ indicate homozygous state, crosses (x) indicate heterozygous state. 


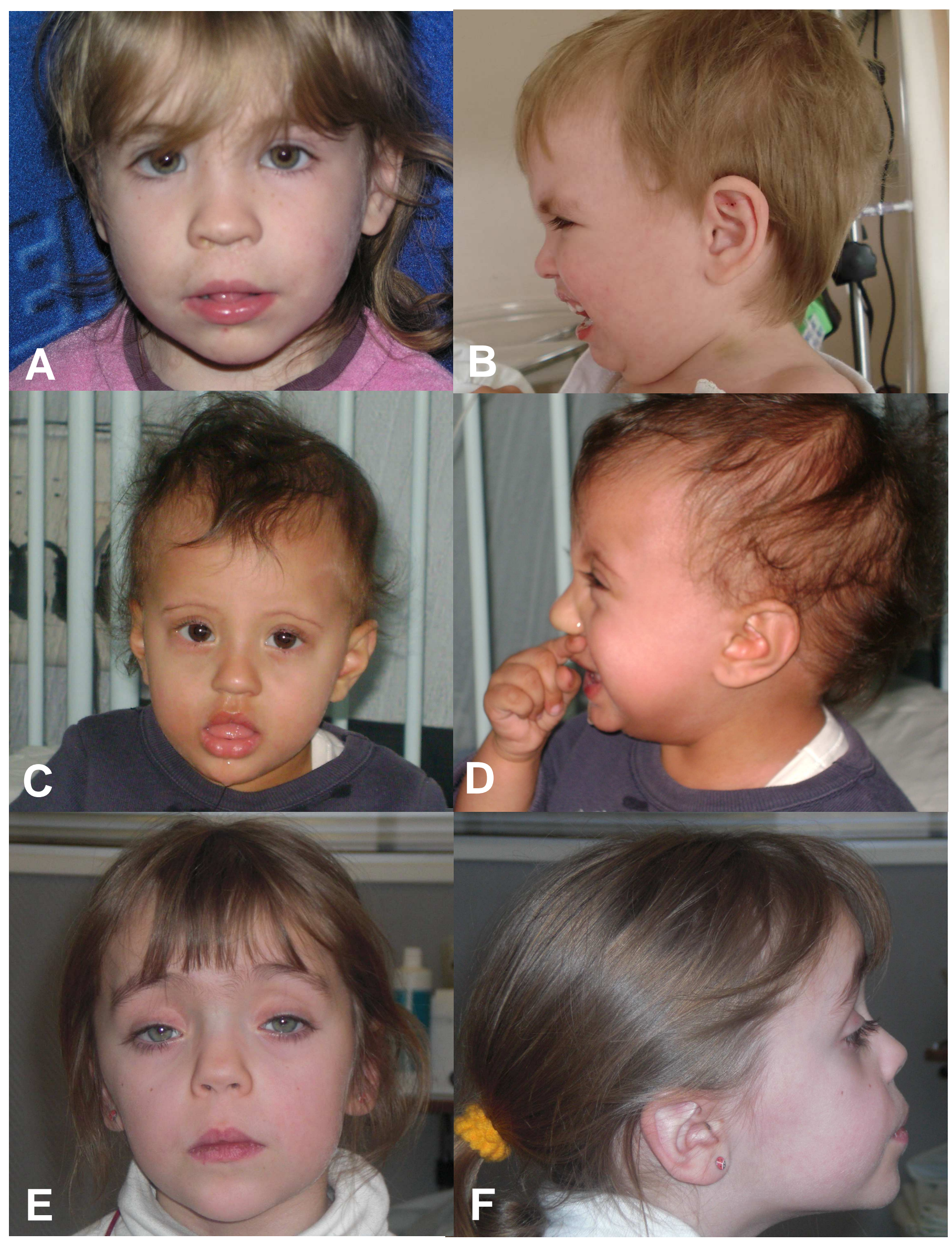




\section{CBL 11q23}

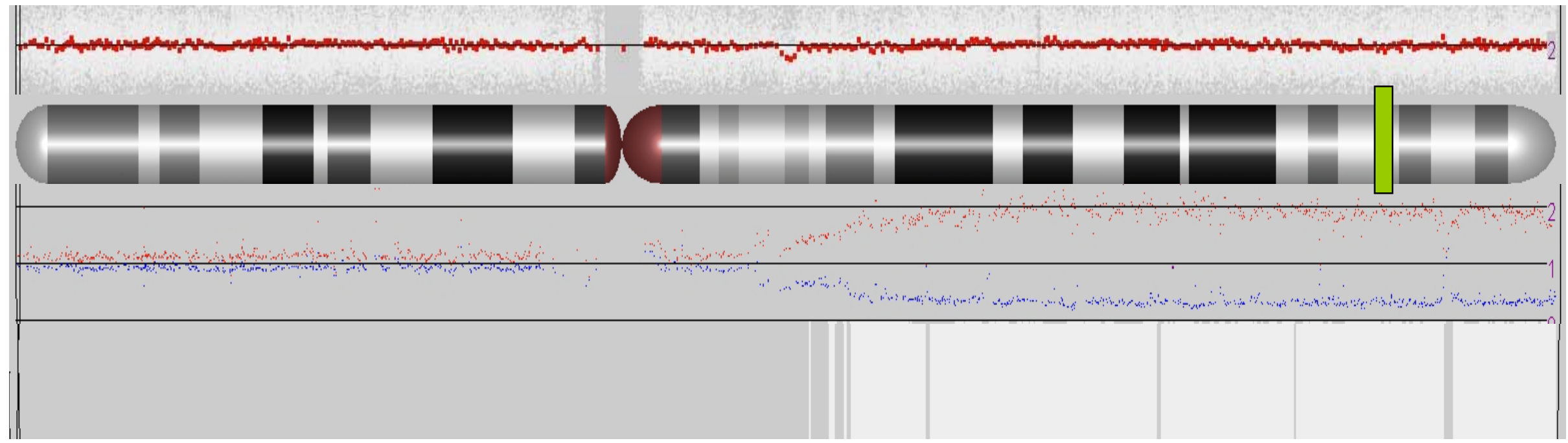

Chromosome 11 


\section{Patient 1}

$\frac{\mathrm{E}}{\mathrm{A} A \mathrm{~T} \text { Т } \mathrm{Y} \text { С } \mathrm{C} \text { Т T }}$

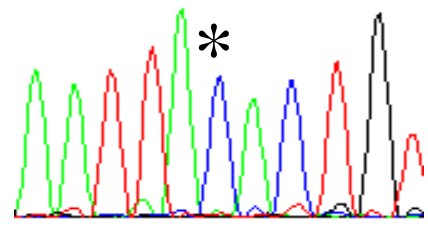

2

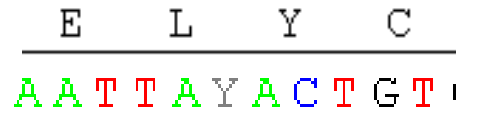

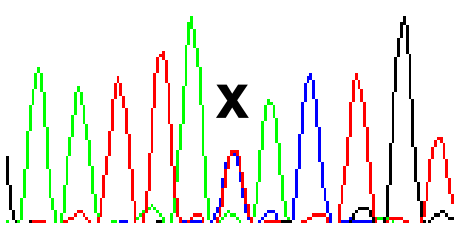

3

4

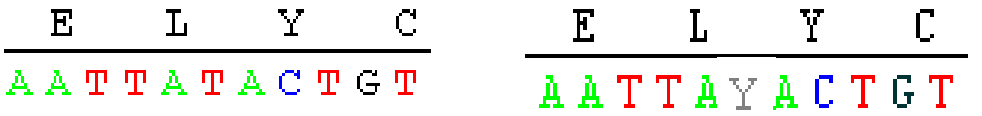

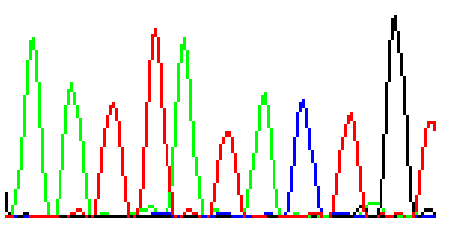

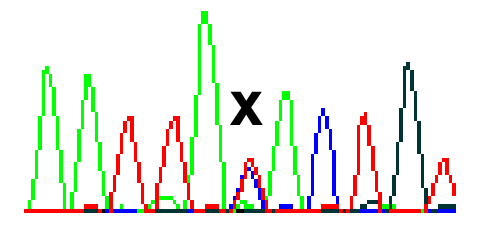

\section{Patient 2}

1

$\frac{\mathrm{E} C \mathrm{~L} \quad \mathrm{C}}{\mathrm{AATTACATGC}}$

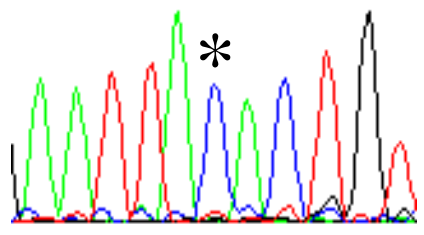

2

\begin{tabular}{cccc}
$\mathrm{E}$ & $\mathrm{L} \quad \mathrm{C}$ \\
\hline A $\mathrm{ATAYACTGT}$
\end{tabular}

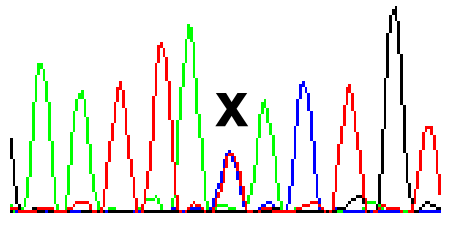

3

$\frac{\mathrm{E}}{\mathrm{A} A \mathrm{ATATACTG}}$

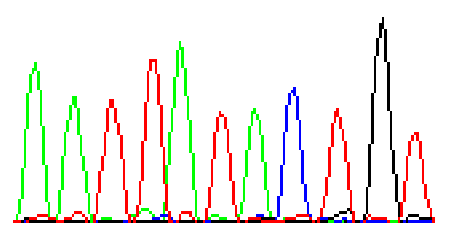

4

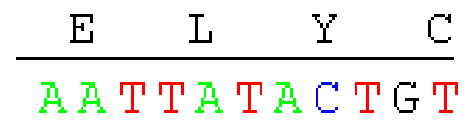

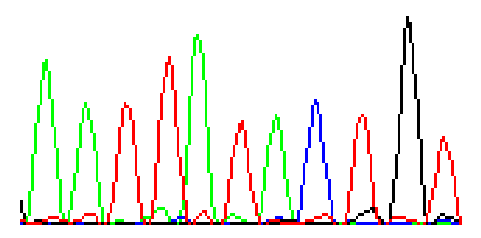

\section{Patient 3}
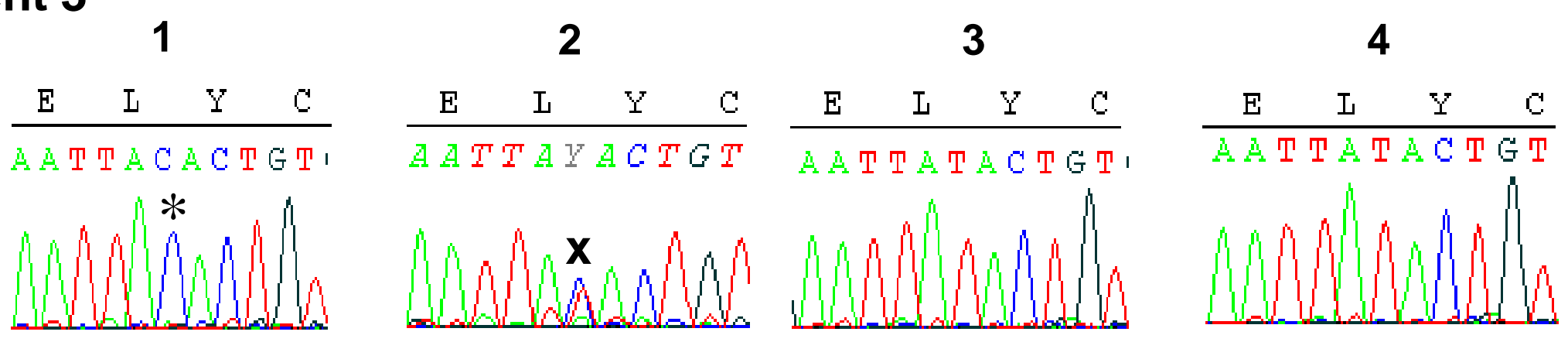